\title{
The peri-urban interface and house infestation with Triatoma infestans in the Argentine Chaco: an underreported process?
}

\author{
Yael M Provecho', M Sol Gaspe ${ }^{1}$, M del Pilar Fernández'1, \\ Gustavo F Enriquez¹, Diego Weinberg², Ricardo E Gürtler ${ }^{1 /+}$
}

${ }^{1}$ Laboratory of Eco-Epidemiology, Department of Ecology, Genetics and Evolution, National Council of Scientific and Technological Research,

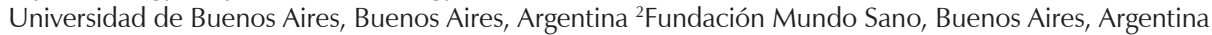

Peri-urban infestations with triatomine bugs, their sources and their dynamics have rarely been investigated. Here, we corroborated the reported occurrence of Triatoma infestans in a peri-urban area and in neighbouring rural houses in Pampa del Indio, in the Argentine Chaco, and identified its putative sources using spatial analysis and demographic questionnaires. Peri-urban householders reported that 10\% of their premises had triatomines, whereas T. infestans was collected by timed manual searches or community-based surveillance in only nine (3\%) houses. Trypanosoma cruzi-infected $\mathrm{T}$. infestans and Triatoma sordida were collected indoors only in peri-urban houses and were infected with $\mathrm{TcV}$ and $\mathrm{TcI}$, respectively. The triatomines fed on chickens, cats and humans. Periurban infestations were most frequent in a squatter settlement and particularly within the recently built mud houses of rural immigrants, with large-sized households, more dogs and cats and more crowding. Several of the observed infestations were most likely associated with passive bug transport from other sources and with active bug dispersal from neighbouring foci. Thus, the households in the squatter settlement were at a greater risk of bug invasion and colonisation. In sum, the incipient process of domestic colonisation and transmission, along with persistent ruralto-urban migratory flows and unplanned urbanisation, indicate the need for active vector surveillance and control actions at the peri-urban interface of the Gran Chaco.

Key words: Trypanosoma cruzi - Triatoma infestans - migration - vector control - reinfestation - urbanisation

The transmission of neglected tropical diseases is closely related to poverty, unplanned urbanisation, weak health services and, more generally, complex interactions between ecological, biological and social factors (Hotez et al. 2008, Charron 2012, Bazzani \& Wiese 2012). Chagas disease, a neglected tropical disease caused by the protozoan Trypanosoma cruzi, which has been grouped into six discrete typing units (DTUs), continues to be a serious public health problem in Latin America and has expanded globally through international migration (WHO 2007). The most important vector of human $T$. cruzi infection is Triatoma infestans, with a wide distribution in the Southern Cone countries of South America. Insecticide-based control campaigns coordinated at the regional level since the early 1990s have severely reduced house infestation indices for $T$. infestans and have reduced or interrupted the vector and blood-borne transmission of human T. cruzi infection in various countries (Dias et al. 2002, Coura \& Dias 2009). However, the rate of progress has been slower in the Gran Chaco region, extending over

doi: $10.1590 / 0074-0276140225$

Financial support: UBA,

Agencia Nacional de Promoción Científica y Técnica

(PICT, PICTO-GLAXO), CONICET (PIP) (to REG)

+ Corresponding author: gurtler@ege.fcen.uba.ar

Received 20 June 2014

Accepted 10 September 2014 sections of Argentina, Bolivia and Paraguay, where the effectiveness of house spraying with pyrethroid insecticides has been much lower than in the more peripheral areas within the range of T. infestans (Gürtler et al. 2007, Gürtler 2009, Gorla et al. 2009, Cecere et al. 2013).

Vector-borne transmission of $T$. cruzi has been closely linked to rural poverty and substandard housing quality. However, several species of triatomine bugs (including $T$. infestans, Triatoma dimidiata, Triatoma pallidipennis and Mepraia spinolai, among others) are able to colonise peri-urban and urban habitats and even invade the top stories of city buildings through flight (Vallvé et al. 1996, Albarracin-Veizaga et al. 1999, Cattan et al. 2002, Ramsey et al. 2005, Levy et al. 2006, GuzmanTapia et al. 2007, Medrano-Mercado et al. 2008, Lima et al. 2012). More specifically, T. infestans has been reported in multiple urban areas of Argentina, Bolivia and Peru and it is frequently associated with human infections (Albarracin-Veizaga et al. 1999, Levy et al. 2006, Carrizo Páez et al. 2008, Medrano-Mercado et al. 2008). The steady rural-to-urban migration recorded during the last century and projected for future decades, combined with increasing travel and transportation of goods from rural to peri-urban or urban areas, might provide multiple routes of entry for triatomine bugs into habitats otherwise considered not to be at risk of infestation. For example, $T$. infestans was carried inadvertently by immigrant workers to a southern Patagonian city approximately $300 \mathrm{~km}$ away from the southernmost limit of the insect's distribution (Piccinali et al. 2010).

Peri-urban areas provide a transition between urban and rural areas and, depending on various factors, may 
offer more precarious housing. Migration and settlement patterns may therefore represent relevant risk factors for house infestation and transmission of T. cruzi (Bayer et al. 2009, Delgado et al. 2013, Levy et al. 2014). Factors associated with house infestation with $T$. infestans in urban or peri-urban areas have occasionally been investigated (Albarracín-Veizaga et al. 1999, MedranoMercado et al. 2008, Levy et al. 2006, 2014), albeit not in the Gran Chaco.

As part of a longitudinal research and control project in rural areas of the Argentine Chaco, we reported a high prevalence of house infestation with $T$. infestans $(40 \%)$ associated with moderate levels of pyrethroid resistance, which caused vector control failures in a rural section of the municipality of Pampa del Indio (Gurevitz et al. 2012). However, house infestation was reduced to below 3\% after sustained monitoring of house reinfestation and selective insecticide spray use over the course of three years (Gurevitz et al. 2013). Between 2008-2013, vector control interventions were scaled up in all rural areas of the municipality until achieving a similar degree of control (RE Gürtler et al., unpublished observations).

During this period, the residents of emerging peri-urban areas in Pampa del Indio occasionally provided anecdotal reports of house infestation with triatomine bugs and records at the local hospital indicated the frequent occurrence of $T$. cruzi-seropositive residents in local peri-urban areas. Based on this information and the success of previous vector control actions, in 2011, local health authorities proposed conducting blanket insecticide spraying of a peri-urban area (Parque Industrial) that had recently sprawled. Standard guidelines for Chagas vector control operations recommend that blanket insecticide sprays be conducted when house infestations with $T$. infestans exceed 5\%. To support the decisionmaking process, we assessed the occurrence and intensity of house infestation and triatomine bug infection with $T$. cruzi in this peri-urban area and in adjacent rural houses. In particular, we used spatial analysis tools to determine whether the distribution of triatomine-positive points was random or aggregated and to infer the underlying process that may have generated the observed pattern (Cecere et al. 2006, Kitron et al. 2006). We also investigated environmental and demographic factors associated with house infestations. As ad hoc hypotheses on the putative sources of peri-urban infestations, we considered that these infestations could represent preexisting, unreported bug colonies; bugs invading from untreated neighbouring foci and bugs brought by newly arrived immigrants originating from infested villages located outside the municipality of Pampa del Indio. Our work provides a case study of ongoing house reinfestation with a major vector species at the interface between peri-urban and rural areas.

\section{MATERIALS AND METHODS}

Study area - Fieldwork was conducted in the municipality of Pampa del Indio ( $\left.25^{\circ} 55^{\prime} \mathrm{S} 56^{\circ} 58^{\prime} \mathrm{W}\right)$, Chaco Province, Argentina (Fig. 1A). According to the national census conducted in 2010, the municipality had approximately 18,000 residents and 3,500 households over an

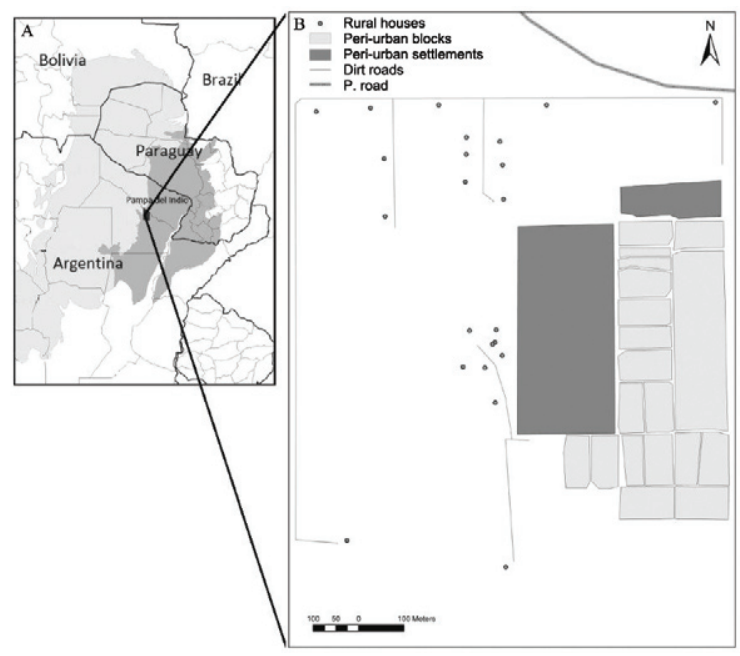

Fig. 1A: Gran Chaco region and location of the study area in Pampa del Indio, Chaco, Argentina; B: map of the study area showing periurban blocks and two settlements (shaded, Parque Industrial) and neighbouring rural houses (Campo Alemany).

area of 2,000 $\mathrm{km}^{2}$ and was among the 50 least developed districts in the country. The annual rate of population increase recorded between the 2001-2010 national censuses was $7 \%$. Approximately half of the total population was of Qom (Toba) descent.

The municipality had last been sprayed with insecticides by the Chaco vector control programme in 1997. As part of the control and research project in Pampa del Indio, all rural houses in the municipality had been sprayed with pyrethroids and kept under sustained vector surveillance via selective control actions since late 20072008. The two areas included in the current study were considered to be part of the urban setting and therefore were not treated at that time. Searches for other sources of house insecticide sprays in the municipality indicated that personnel from the local hospital evaluated infestations selectively and sprayed 38 houses in Parque Industrial with pyrethroids, 14 (36.8\%) of which were infested with T. infestans, in September 2006.

Parque Industrial is a $0.5 \mathrm{~km}^{2}$ peri-urban neighbourhood that included 21 blocks with 293 inhabited households $(54.5 \%$ of Creole descent and $45.5 \%$ Qom) in mid-2011 (Fig. 1B). The houses were either built with mortared brick walls and a tin roof ("social-plan housing") or were more precarious and had walls made with wood planks, mud and grass (torta) or fabric and roofs of metal or corrugated tarred cardboard (Fig. 2). A squatter settlement comprising two sections, with 140 and 50 houses, emerged in 2009-2010. Only 97 houses were occupied and the remaining houses were under construction or uninhabited; $49 \%$ of them were owned by Qom households. In contrast to other rural or peri-urban houses, the main construction material in the settlement was mud (72\%); few houses had mud or cement-mortared bricks (19.6\%) or used other materials (7.2\%). Most dwellers $(70.5 \%)$ arriving during the previous 12 months were from rural areas of Pampa del Indio that were under sustained vector surveillance and selective control. 

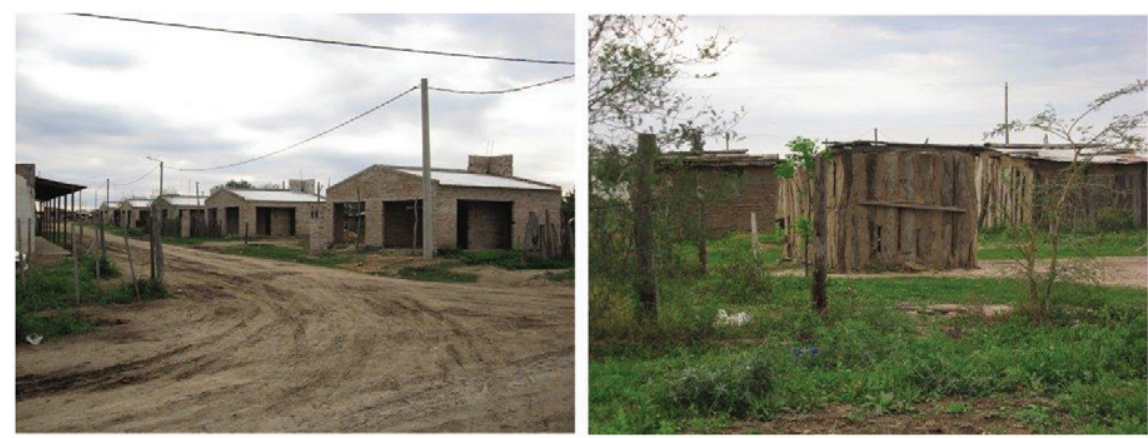

Fig. 2: peri-urban houses in Parque Industrial, Chaco, Argentina. A: built with mortared brick walls and metal roof; B: mud and grass precarious houses in the squatter settlement.

The peri-urban area had a regular distribution of houses with clearly defined parcel limits, very few peridomestic structures and few domestic animals.

The nearby rural village Campo Alemany was approximately $100 \mathrm{~m}$ from Parque Industrial (Fig. 1B) and included 23 houses (20 inhabited) with poorly defined borders, five of which were owned by Creoles and 15 by Qom families. Most of these houses had mud walls and a few had mortared brick walls. In total, $70 \%$ of all houses had multiple peridomestic structures, including chicken coops and corrals.

Study design - A longitudinal survey of house infestation combined with environmental and demographic baseline surveys were conducted in both areas between 2011-2012. All houses were surveyed for triatomine bugs at least once and environmental and sociodemographic variables were recorded.

House surveys - Healthcare workers from the local hospital conducted a preliminary rapid survey of house infestation in the peri-urban area in May 2011; 70.8\% of the 293 inhabited houses were visited and the residents were asked whether there were triatomine bugs in their premises (i.e., no insects were shown to residents). Additionally, a house census survey of the peri-urban area was conducted in September 2011. Each house was identified with a numbered aluminium plate and georeferenced with a GPS receiver (Garmin Legend) and all house locations were mapped using ArcGIS 9.2. An adult member of each household was interviewed to collect the following data: the name of the household head, the number of residents in each age group (0-4, 5-14 and older than 15 years of age), ethnic group, the types and numbers of domestic animals (dogs, cats, chickens and other), domestic use of insecticides and whether any householder had observed triatomines within the house premises. To prevent the misidentification of other insects as triatomines (including failure to distinguish between $T$. sordida and $T$. infestans), dry specimens of these species and other Reduviidae were shown to householders to allow more accurate identification. A trained observer recorded the materials used in the construction of the walls and roof and visually determined the availability level of potential refuges for triatomine bugs, with five levels ranging from an absence of refuges to abundant refuges (Gurevitz et al. 2011).
Sociodemographic variables potentially associated with infestation in the peri-urban houses were recorded: the presence of wardrobes and boxes containing clothes, the length of residence in the current peri-urban area, the age of the house (years since it was built), the residents' village of origin, contact with the village of origin (i.e., whether the residents still owned the previous house and stayed there overnight), the occurrence of house infestations in the village of origin before moving into the current peri-urban area, transportation of house construction materials and other goods to the current house, renovations of the current house, the size of the domestic area and total occupied terrain $\left(\mathrm{m}^{2}\right)$ and the numbers of beds and bed places. This information was used to compute two crowding indices: the number of human occupants per $\mathrm{m}^{2}$ (density) and per bed place.

All houses were inspected for triatomine bugs by two experienced technicians from the Chagas vector control programme using a tetramethrin-based aerosol (Espacial, $0.2 \%$ tetramethrin) to dislodge the insects from their refuges. Human sleeping quarters (domiciles) were inspected for $20 \mathrm{~min}$ and each peridomestic site or structure that could serve as a potential refuge for the bugs was inspected by another person for $15 \mathrm{~min}$. All collected bugs were identified to the species level, counted and sexed, as described elsewhere (Gurevitz et al. 2011). All rural houses and the peri-urban houses infested with $T$. infestans were then sprayed with deltamethrin suspension concentrate (SC) (K-Othrin, Bayer) using routine procedures (Gurevitz et al. 2012).

Household heads were provided with a labelled plastic bag to keep any triatomine bugs that they could catch in the domestic and peridomestic sites in their homes and were instructed on how to do so without incurring any contamination risk. As part of community-based vector surveillance, householders were requested to bring the insects to the local hospital (at a distance of approximately $1.5-2 \mathrm{~km}$ ).

In the second vector survey, conducted in May 2012, all inhabited houses were visited and the residents were asked whether they had observed triatomine bugs in their premises since our last visit (in September 2011). A total of 127 peri-urban houses ( $41 \%$ of all inhabited houses) and nine rural houses (50\% of all inhabited houses) that were selected systematically were inspected for triatomine bugs using the same procedures as in the baseline 
survey. Following notifications of house infestations in February 2014, local vector control personnel surveyed all dwellings in the block including the infested house and in a neighbouring rural house to identify the putative origin of the reported infestations. The houses infested with $T$. infestans were selectively sprayed with deltamethrin $\mathrm{SC}$, as before.

Bug infection and bloodmeal analysis - Live thirdinstar nymphs and older stages, including two live $T$. sordida specimens collected indoors, were examined for infection with T. cruzi by direct microscopic observation (MO) at 400X. Both live and dead (well-preserved) specimens of T. sordida and T. infestans collected in human sleeping quarters were examined by kDNA-polymerase chain reaction (PCR), as described elsewhere (Maffey et al. 2012). In reference to the relative sensitivity of MO and kDNA-PCR, $13 \%$ of $T$. infestans bugs that had been MO-negative in xenodiagnosis of $T$. cruzi-infected dogs were kDNA-PCR positive (Enriquez et al. 2014) and $7.5 \%$ of field-collected MO-negative $T$. infestans specimens tested positive by kDNA-PCR (Marcet et al. 2006). DTUs were identified from T. cruzi-infected triatomines using direct PCR strategies, as described by Maffey et al. (2012).

The bloodmeal sources of all bugs collected in the peri-urban area and of a sample of those collected in rural houses were identified using a direct ELISA that detects human, dog, cat, chicken, pig and goat antigens and that has high sensitivity and specificity values, as described (Gürtler et al. 2009, 2014).

Statistical analysis - Because the infestation prevalence was very low, the data for house infestation with $T$. infestans were pooled across surveys and collection methods and analysed by Firth penalised logistic regression for rare events implemented in Stata 12 (StataCorp 2012). Firth penalised logistic regression produces finite, consistent estimates of regression parameters when maximum likelihood estimates do not exist because of complete or quasi-complete data separation and thus reduces smallsample bias (Heize \& Schemper 2002). Multicollinearity was checked by variance inflation factor estimates.

A multivariate analysis of risk factors for domestic infestation in the peri-urban area included demographic and environmental variables (ethnic group, the number of people per house, wall building materials, insecticide use, the number of cats per house, the residence period in the peri-urban area, the village of origin of the residents and the transport of belongings from the former rural house).

The spatial distribution of houses surveyed by healthcare workers and of houses with a reported infestation or with $T$. infestans detected by timed manual searches or householders was assessed by a global, local and focalpoint pattern analysis (PPA) implemented in Programita and PPA (Chen \& Getis 2003, Wiegand \& Moloney 2004). Ripley's L-function with a K-function statistic was used for global spatial analysis. The random-labelling method was chosen as the null hypothesis; it assesses the spatial distribution of points with a given attribute (i.e., infested houses), allowing for determination of the spatial distribution of all points (i.e., all houses inspected for infestation). The grid size was $20 \mathrm{~m}$ and $47 \mathrm{~m}$ for the surveyed houses and infested houses, respectively, and the maximum search radius was $300 \mathrm{~m}$. To detect local $\left[\mathrm{G}^{*}(\mathrm{~d})\right]$ and focal $[\mathrm{G}(\mathrm{d})]$ spatial aggregation, PPAbased analyses were performed with a search radius of 0-300 $\mathrm{m}$ and a $50 \mathrm{~m}$ interval determined by the smallest distance between infested houses. The null hypothesis was that the infested houses were randomly distributed. We predicted that the more abundant foci were spatially aggregated (in a local analysis) and that the infested sites were aggregated around infested sites with abundant bug colonies (focal analysis).

A putative source was defined as any large focus of $T$. infestans around which smaller foci were detected (with aggregation determined by PPA) or, more generically and tentatively, as the putative origin of the bugs found at a site, given the circumstantial evidence provided by the house-dwellers (Cecere et al. 2006).

\section{RESULTS}

Infestation - Peri-urban householders reported their premises to be infested with triatomine bugs with nearly the same frequency in May 2011 (10.9\%) and September $2011(9.9 \%)$. The degree of agreement between the two reports was very poor (kappa index $=0.1$ ). Of the 20 respondents who reported bug-infested premises, $75 \%$ recognised $T$. infestans, $25 \%$ recognised $T$. sordida and $5 \%$ recognised other insects (not triatomines) as the culprit.

In contrast, parallel timed manual searches collected triatomine bugs only in $1.7 \%$ of the peri-urban houses in September 2011; the catches included T. infestans in the domiciles of two $(0.7 \%)$ houses (1 consisting of an

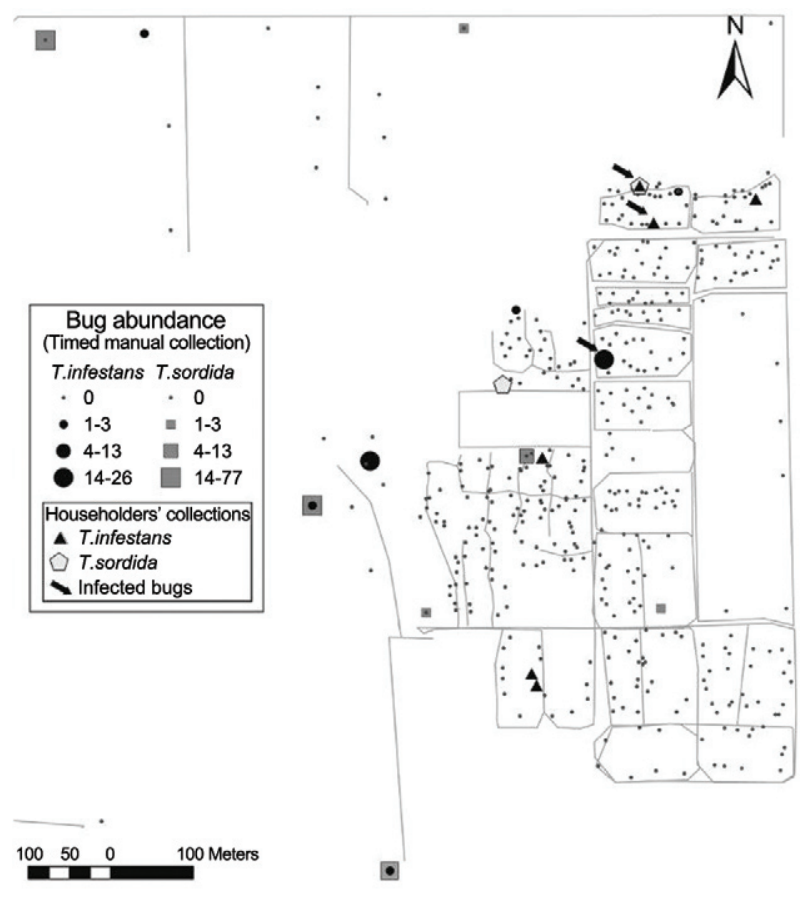

Fig. 3: spatial distribution and abundance of Triatoma infestans and Triatoma sordida by timed manual searches pooled over 2011 and 2012 surveys and householders' bug collections and occurrence of bug infection with Trypanosoma cruzi, Pampa del Indio, Chaco, Argentina. 


\section{TABLE I}

Distribution of infested houses and prevalence of Trypanosoma cruzi infection in Triatoma infestans and Triatoma sordida determined by direct microscopic observation (MO) and kDNA-polymerase chain reaction (PCR) according to survey date and collection method in a peri-urban area and adjacent rural houses of Pampa del Indio, Chaco, Argentina

Infected bugs/bugs examined $\mathrm{n} / \mathrm{n}$

\begin{tabular}{|c|c|c|c|c|c|c|c|c|}
\hline \multirow[b]{2}{*}{ Area } & \multirow[b]{2}{*}{ Collection date } & \multirow[b]{2}{*}{$\begin{array}{l}\text { Collection } \\
\text { method }\end{array}$} & \multicolumn{2}{|c|}{$\begin{array}{l}\text { Infested houses/inspected } \\
\text { houses (bugs collected) } \\
\text { n/n (n) }\end{array}$} & \multicolumn{2}{|c|}{$\mathrm{MO}$} & \multicolumn{2}{|c|}{ kDNA-PCR } \\
\hline & & & $\begin{array}{c}T . \\
\text { infestans }\end{array}$ & $\begin{array}{c}T . \\
\text { sordida }\end{array}$ & $\begin{array}{c}T . \\
\text { infestans }\end{array}$ & $\begin{array}{c}T . \\
\text { sordida }\end{array}$ & $\begin{array}{c}T . \\
\text { infestans }\end{array}$ & $\begin{array}{c}T . \\
\text { sordida }\end{array}$ \\
\hline \multirow[t]{4}{*}{ Peri-urban } & September 2011 & Timed manual $^{a}$ & $2 / 293(15)$ & 3/293 (9) & $3 / 7$ & $0 / 1$ & $3 / 7$ & $0 / 1$ \\
\hline & May 2012 & Timed manual $^{a}$ & $1 / 118(2)$ & $0 / 118(0)$ & $0 / 2$ & - & $0 / 2$ & - \\
\hline & $\begin{array}{l}\text { November } 2011 \\
\text { February } 2014\end{array}$ & Householders & $6(11)$ & $2(4)$ & $0 / 3$ & $0 / 1$ & $2 / 8^{b}$ & $1 / 4^{b}$ \\
\hline & Subtotal $(\%)^{c}$ & & 3.1 & 1.7 & 25 & 0 & 29.4 & 20 \\
\hline \multirow[t]{3}{*}{ Rural } & September 2011 & Timed manual $^{a}$ & $4 / 20(47)$ & 4/20 (189) & $0 / 27$ & - & $0 / 6$ & - \\
\hline & May 2012 & Timed manual $^{a}$ & $0 / 9$ & $1 / 9(5)$ & - & - & - & - \\
\hline & Subtotal $(\%)^{c}$ & & 20 & 25 & 0 & - & 0 & - \\
\hline
\end{tabular}

$a$ : includes insects collected immediately after timed manual searches; $b$ : live triatomines (3rd-instar nymphs and larger stages) were analysed by MO and kDNA-PCR and dead specimens were examined by kDNA-PCR; $c$ : percentage of infested houses among those inspected by any method and percentage of infected triatomines among all insects examined by at least one method.

adult bug and the other consisting a bug colony comprising all stages) and T. sordida in the chicken coops of three houses (1\%) (Fig. 3, Table I). The follow-up vector survey yielded $T$. infestans only in one house $(0.8 \%)$, with no T. sordida, in May 2012; 4.6\% of householders reported having observed triatomine bugs inside their sleeping quarters.

As part of the community-based surveillance system, during the follow-up survey, one household provided two triatomines of each species that had been caught indoors. Another three households in the settlement captured six T. infestans and two T. sordida specimens after being bitten inside their mud-built houses between November 2011-February 2013 and brought them to the local hospital. Similarly, dwellers from two peri-urban houses captured and provided three adult $T$. infestans specimens indoors in February 2014 (Fig. 3, Table I). During searches for the putative sources of these infestations, local vector control personnel captured T. infestans in the chicken coop of an adjacent rural house (in Campo Alemany) that had been positive for both triatomine species in 2011 (Fig. 3). Overall, T. infestans was collected in nine (3.1\%) different peri-urban houses among the 293 houses included in the study.

Of the 13 peri-urban households in which triatomine bugs of any species were collected by any method between September 2011-February 2014, only two had reported a bug infestation during the preliminary rapid survey in May 2011. In contrast, no bug was subsequently collected at 18 houses that had reported an infestation (Fig. 4).
In the adjacent rural houses, the overall infestation prevalence of $T$. infestans $(20 \%)$ was six-fold greater than in the peri-urban area (3.1\%). At baseline, we collected $47 T$. infestans specimens from three domiciles and two chicken coops at four houses and 189 T. sordida specimens (all but 1 in chicken coops) at four houses (Fig. 3, Table I). Eight months after the community-wide insecticide spraying, the follow-up survey found no house positive for $T$. infestans and only one house with $T$. sordida in a chicken coop, though $5.5 \%$ of householders reported having observed triatomine bugs inside their domiciles.

Bug infection, DTU identification and bloodmeal analysis - T. cruzi-infected T. infestans specimens were collected at three of the seven peri-urban houses, but at neither of the two rural houses with bugs examined for infection, whereas infected T. sordida was found in one of the two peri-urban houses in which it was collected in human sleeping quarters. The percentage of peri-urban T. infestans infected with T. cruzi varied from $25 \%$ (MO) in live specimens to $29 \%$ (kDNA-PCR) in live or dead specimens (Table I); these specimens were all captured in domiciles. One of the nine MO-negative bugs tested by kDNA-PCR was positive, whereas three bugs were positive by both MO and kDNA-PCR. One of the four adult T. sordida specimens captured indoors was kDNA-PCR positive for T. cruzi. In contrast, none of the bugs collected in rural houses was MO or kDNA-PCR positive. TcV was identified in two T. cruzi-infected T. infestans and TcI in the only $T$. sordida-infected specimen. DTU identifications were unsuccessful for three $T$. infestans specimens due to the small amounts of DNA in the samples. 
TABLE II

Distribution of bloodmeal sources in Triatoma infestans and Triatoma sordida in a peri-urban area and adjacent rural houses of Pampa del Indio, Chaco, Argentina

\begin{tabular}{|c|c|c|c|c|c|c|c|c|c|c|}
\hline \multirow[b]{2}{*}{ Triatomine species } & \multirow[b]{2}{*}{ Area } & \multicolumn{9}{|c|}{$\begin{array}{l}\text { Bugs fed on } \\
\text { n (\%) }\end{array}$} \\
\hline & & $\begin{array}{l}\text { Bugs } \\
\text { tested } \\
\text { (n) }\end{array}$ & $\begin{array}{c}\text { Reactive } \\
\text { bugs } \\
\text { n (\%) }\end{array}$ & Human & Cat & Chicken & Dog & Goat & Pig & $\begin{array}{c}\text { Bugs } \\
\text { with mixed } \\
\text { blood meals } \\
\mathrm{n}(\%)\end{array}$ \\
\hline \multirow[t]{3}{*}{ T. infestans } & Peri-urban & 14 & $8(57)$ & $3(38)$ & $2(25)$ & $4(50)$ & $0(0)$ & $0(0)$ & $0(0)$ & $1(13)$ \\
\hline & Rural & 15 & $13(87)$ & $4(31)$ & $6(46)$ & $5(38)$ & $0(0)$ & $0(0)$ & $0(0)$ & $2(15)$ \\
\hline & Subtotal & 29 & $21(72)$ & 7 (33) & $8(38)$ & $9(43)$ & $0(0)$ & $0(0)$ & $0(0)$ & $3(14)$ \\
\hline T. sordida & Peri-urban & 13 & $9(69)$ & $0(0)$ & $1(11)$ & $8(89)$ & $0(0)$ & $0(0)$ & $0(0)$ & $0(0)$ \\
\hline
\end{tabular}

Bloodmeal identification tests showed that of the 21 ELISA-reactive T. infestans specimens, 33\% had fed on humans; $38 \%$, on cats, and $43 \%$, on chickens, and that $14 \%$ had had mixed bloodmeals from cats and chickens (Table II). However, the bloodmeal sources could not be determined in the triatomines with identified DTUs due to a lack of bloodmeal contents. Of nine reactive T. sordi$d a$ specimens, eight had fed on chickens and one had fed on cats. In the peri-urban area, the T. infestans specimens collected in domiciles had fed on chickens, humans and cats, whereas the only reactive $T$. sordida specimen collected indoors had fed on cats. Both triatomine species collected in chicken coops had fed mainly on chickens. Among the T. cruzi-infected bugs, the only reactive $T$. infestans specimen had fed on humans. In rural houses, domestic $T$. infestans had fed on humans or cats and bugs from chicken coops had fed on chickens or cats.

Spatial analysis - Peri-urban house infestations with T. infestans and T. sordida occurred largely along the periphery, at the interface with the rural area and mainly in the two settlements where housing was more precarious and households had recently immigrated (Figs 3, 4). Conversely, a large fraction of houses in the eastern section of the peri-urban area were of good quality, had long been established and had used domestic insecticides more frequently. All but one of the infestations detected in 2006 occurred in this group of households.

The spatial analysis did not reveal global aggregation of triatomine infestations in either the rapid survey (based on householders' reports) or the subsequent collections of T. infestans pooled across surveys and methods (Figs 3, 5). Local aggregation of $T$. infestans was found within $120 \mathrm{~m}$ of the highly infested chicken coop of a rural house in Campo Alemany. The distance between the latter and the most distant house positive for T. infestans was 596 $\mathrm{m}$ (i.e., within the known flight range of the vector). In contrast, in the peri-urban settlements, although no statistically significant clustering of infestation was revealed, the infested houses were within $100 \mathrm{~m}$ of each other.
Risk factors - House infestation was more frequent in Creole than in Qom households among the rural houses ( $40 \%$ vs. $13.3 \%$, respectively), but this difference was not present in the peri-urban area $(2.4 \%$ in both ethnic groups) (Table III). Houses containing mud were significantly more frequently infested (4.2-5.4\%) than the other types of construction were, with fewer refuges for the bugs (brick and cement, canvas or clothing). All infesta-

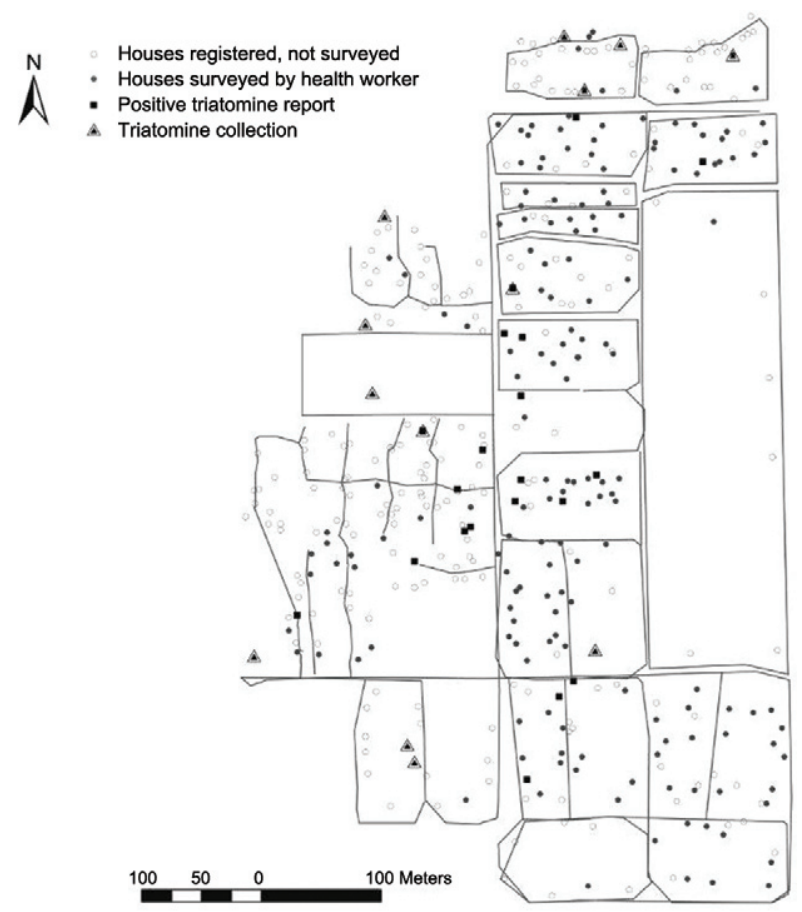

Fig. 4: spatial distribution of houses surveyed by healthcare workers in May 2011, houses reported infested by householders at baseline and houses infested by Triatoma infestans or Triatoma sordida as determined by timed manual searches or householders' collections, Pampa del Indio, Chaco, Argentina. 
TABLE III

Distribution of house infestation with Triatoma infestans according to demographic and environmental variables in a peri-urban area and adjacent rural houses of Pampa del Indio, Chaco, Argentina

\begin{tabular}{|c|c|c|c|c|c|c|}
\hline \multirow[b]{2}{*}{ Variables } & \multicolumn{3}{|c|}{$\begin{array}{c}\text { Infested houses (inspected houses) } \\
\%(\mathrm{n})\end{array}$} & \multicolumn{3}{|c|}{ Crude odds ratio } \\
\hline & Peri-urban & Rural & Total & Peri-urban & Rural & Total \\
\hline \multicolumn{7}{|l|}{ Ethnic group } \\
\hline Creole & $2.4(165)$ & $40(5)$ & $3.5(170)$ & 1 & 1 & 1 \\
\hline Qom & $2.4(127)$ & $13.3(15)$ & $3.5(142)$ & $1.0(0.2-4.2)$ & $0.2(0.1-2.1)$ & $1.0(0.3-3.2)$ \\
\hline \multicolumn{7}{|l|}{ Insecticide use } \\
\hline No & $0(66)$ & $0(1)$ & $0(67)$ & 1 & 1 & 1 \\
\hline Yes & $3.2(217)$ & $21.1(19)$ & $4.7(236)$ & $4.7(0.3-84.1)$ & $0.9(0.1-25.3)$ & $6.9(0.4-118.3)$ \\
\hline \multicolumn{7}{|l|}{ Wall building materials ${ }^{a}$} \\
\hline Mud-and-grass & $4.7(128)$ & $100(1)$ & $5.4(129)$ & $16.5(0.9-295.8)$ & $21.0(0.6-791.3)$ & $6.8(1.2-39.6)^{b}$ \\
\hline Brick-and-mud & $0(10)$ & $7.1(14)$ & $4.2(24)$ & $14.8(0.3-784.2)$ & $0.8(0.7-8.6)$ & $7.0(0.7-70.5)$ \\
\hline Brick-and-cement & $0(155)$ & $9.1(11)$ & $0.6(166)$ & 1 & 1 & 1 \\
\hline Canvas, cloth, others & $0(20)$ & - (0) & $0(20)$ & $7.6(0.1-392.7)$ & - & $4.7(0.1-68.3)$ \\
\hline \multicolumn{7}{|l|}{ Refuge availability $^{a}$} \\
\hline $1-2$ (no refuge) & $0(39)$ & $0(3)$ & $0(42)$ & 1 & 1 & 1 \\
\hline 3 & $4.7(64)$ & $33.3(6)$ & $7.1(70)$ & $4.5(0.2-89.4)$ & $3.9(0.1-110.0)$ & $7.1(0.4-132.4)$ \\
\hline 4-5 (abundant refuge) & $9.1(33)$ & $9.1(11)$ & $9.1(44)$ & $9.1(0.5-182.2)$ & $1.0(0.1-30.6)$ & $9.4(0.5-181.0)$ \\
\hline \multicolumn{7}{|l|}{ People per house } \\
\hline $1-2$ & $0(61)$ & $0(5)$ & $0(66)$ & 1 & 1 & 1 \\
\hline $3-5$ & $2(147)$ & $25(4)$ & $2.7(151)$ & $3.0(0.2-58.5)$ & $4.7(0.1-151.5)$ & $4.1(0.2-76.5)$ \\
\hline$\geq 6$ & $4.8(83)$ & $27.3(11)$ & $7.5(94)$ & $7.0(0.4-131.8)$ & $4.5(0.2-105.8)$ & $11.4(0.6-203.2)$ \\
\hline \multicolumn{7}{|l|}{ Dogs per house } \\
\hline 0 & $0.8(129)$ & $0(1)$ & $0.8(130)$ & 1 & 1 & 1 \\
\hline $1-2$ & $3.9(128)$ & $0(8)$ & $3.7(136)$ & $3.6(0.6-23.6)$ & $0.2(0.0-12.8)$ & $3.6(0.6-22.3)$ \\
\hline$\geq 3$ & $2.9(35)$ & $36.4(11)$ & $10.9(46)$ & $3.7(0.4-36.9)$ & $1.8(0.1-54.33)$ & $11.4(1.8-72.0)^{b}$ \\
\hline \multicolumn{7}{|l|}{ Cats per house } \\
\hline 0 & $1.4(223)$ & $15.4(13)$ & $2.1(236)$ & 1 & 1 & 1 \\
\hline$\geq 1$ & $5.8(69)$ & $28.6(7)$ & $7.9(76)$ & $4.3(1.1-18.0)^{b}$ & $2.1(0.3-15.9)$ & $3.9(1.2-12.5)^{b}$ \\
\hline \multicolumn{7}{|l|}{ Occupants per bed-place } \\
\hline$<1$ & $0(65)$ & NR & $0(65)$ & 1 & - & 1 \\
\hline 1 & $1.9(52)$ & NR & $1.9(52)$ & $3.8(0.2-95.6)$ & - & $3.8(0.2-95.6)$ \\
\hline$>1<2$ & $5.8(87)$ & NR & $5.8(87)$ & $8.7(0.5-160.8)$ & - & $8.7(0.5-160.8)$ \\
\hline$\geq 2$ & $2.1(48)$ & NR & $2.1(48)$ & $4.1(0.2-103.8)$ & - & $4.1(0.2-103.8)$ \\
\hline
\end{tabular}

$a$ : calculated considering each domicile separated; $b: \mathrm{p}<0.05$; NR: not recorded.

tions occurred in households reporting domestic use of insecticides. In peri-urban households, the prevalence of house infestation increased steadily, with greater availability of bug refuges, a larger household size and a greater number of cats. The infested houses were also significantly more crowded than the non-infested houses were (Mann-Whitney $U$, degree of freedom $=1 ; p<$ $0.05)$. Overall, house infestation was significantly associated with the wall building materials and the presence of at least one cat and more than three dogs. When modelling the demographic and environmental factors, wall building materials were the only factor involved in the final model $(\mathrm{p}=0.01)$.
Peri-urban households with less than two years of local residence were more frequently infested (5.5\%) than those of two-five years $(0.9 \%)$ or more than five years $(0 \%)$ of local residence (Table IV). Local residence time was very closely correlated with the age of the house. More frequent infestations $(5.3 \%)$ occurred in the premises of households that had immigrated from rural areas under no vector control compared with those households that came from other peri-urban areas under no vector surveillance $(3.2 \%)$ or from rural areas under surveillance $(1.8 \%)$. House infestation was found at a similar frequency in households that reported triatomines in their previous house $(2.9 \%)$ and in those that did not $(2.9 \%)$. 


\section{TABLE IV}

Distribution of house infestation with Triatoma infestans according to migration features in a peri-urban area of Pampa del Indio, Chaco, Argentina

\begin{tabular}{|c|c|c|}
\hline Variables & $\begin{array}{c}\text { Infested houses } \\
\text { (inspected houses) } \\
\%(n)\end{array}$ & $\begin{array}{c}\text { Crude } \\
\text { odds ratio }\end{array}$ \\
\hline \multicolumn{3}{|l|}{ Residence period in peri-urban area (years) } \\
\hline $0-1$ & $5.5(109)$ & 1 \\
\hline $2-5$ & $0.9(117)$ & $0.2(0.1-1.2)$ \\
\hline$>5$ & $0(62)$ & $0.1(0.1-2.3)$ \\
\hline \multicolumn{3}{|l|}{ Housing improvements in domicile } \\
\hline Yes & $2.1(97)$ & 1 \\
\hline No & $3.5(142)$ & $1.52(0.3-7.0)$ \\
\hline \multicolumn{3}{|l|}{ Migration from rural area } \\
\hline Yes & $2.2(185)$ & 1 \\
\hline No & $2.9(103)$ & $1.4(0.3-5.8)$ \\
\hline \multicolumn{3}{|l|}{ Village of origin } \\
\hline Rural under vector surveillance & $1.8(164)$ & 1 \\
\hline Rural with no vector control actions & $5.3(19)$ & $3.8(0.5-26.9)$ \\
\hline Peri-urban with no vector control actions & $3.2(94)$ & $1.8(0.4-8.0)$ \\
\hline \multicolumn{3}{|l|}{ Presence of triatomine bugs in the village of origin } \\
\hline Yes & $2.9(138)$ & 1 \\
\hline No & $2.9(104)$ & $1.0(0.2-4.3)$ \\
\hline \multicolumn{3}{|l|}{ Still owning the former rural house } \\
\hline Yes & $0.9(118)$ & 1 \\
\hline No & $4.8(84)$ & $4.4(0.7-28.4)$ \\
\hline \multicolumn{3}{|l|}{ Carrying of belongings from the former rural house } \\
\hline Yes & $7.1(70)$ & $5.7(0.9-35.4)$ \\
\hline No & $1(102)$ & 1 \\
\hline \multicolumn{3}{|l|}{ Presence of wardrobe } \\
\hline Yes & $1.6(194)$ & 1 \\
\hline No & $4.9(81)$ & $3.2(0.8-13.2)$ \\
\hline \multicolumn{3}{|l|}{ Presence of boxes with clothes } \\
\hline Yes & $5.5(127)$ & 1 \\
\hline No & $0(0)$ & $17.4(1.0-307.2)^{a}$ \\
\hline
\end{tabular}

$a: \mathrm{p}<0.05$.

Householders who reported still owning their house in their village of origin $(0.9 \%)$ had much lower house infestation than those who did not (4.8\%). Households that brought their belongings from the previous house (7.1\%) or had no wardrobes $(4.9 \%)$ had higher infestation rates than those that did not bring their belongings $(1 \%)$ or that had wardrobes $(1.6 \%)$. Additionally, households that kept clothes in boxes $(5.5 \%)$ had significantly higher infestation rates $(5.5 \%)$ than those with no boxes $(0 \%)$. Although these variables show expressive trends, none of the factors related to the migration processes was associated with peri-urban infestation in either the univariate or the multivariate analysis.
Putative origins of house infestations - The two periurban houses positive for $T$. infestans at baseline were precarious. One of the households had immigrated six months before from another municipality that was under no vector surveillance and had brought all of the house construction materials with them and they reported that their previous house had been infested (i.e., putative passive transport from elsewhere). The second household had moved in with their belongings two years before from an infested shack located within the same periurban area (their bugs had been provided to us) (i.e., passive transport within the peri-urban study area). In the follow-up vector survey, the dwellers of a T. infestans- 
positive house reported having dismantled a chicken coop with a large triatomine infestation several days before our search; this household had immigrated from another district over the previous year and reported that the previous house was non-infested. The closest neighbour to this highly infested house provided two $T$. infestans specimens and two adult $T$. sordida specimens captured in sleeping quarters; one of each species was positive for T. cruzi (i.e., a secondary focus most likely originating from the neighbouring chicken coop at $10 \mathrm{~m}$ ).

The three households located at the settlement's periphery that collected $T$. infestans between vector surveys had been negative at baseline and were negative after being sprayed with insecticide and none had a history of travelling to other locations. These infestations occurred at 90-200 m from two highly infested chicken coops. Moreover, householders' collections of $T$. infestans in early 2014 occurred at $250 \mathrm{~m}$ from an infested chicken coop in the adjacent rural area.

\section{DISCUSSION}

Our results document the occurrence of both $T$. infestans and T. sordida infected with T. cruzi in the sleeping quarters of houses in a peri-urban area in the Argentine Chaco, indicating the initial phase of a (re-)emerging process of domestic colonisation and active transmission, at a time when domestic triatomine bug abundance was still low. By linking house infestations to migration history, settlement patterns and household attributes, our data suggest that different sources generated the observed pattern: passive bug transport from elsewhere and within the peri-urban area and foci originating from adjacent foci, from which adult bugs dispersed actively and invaded precarious houses in the squatter settlement. Unrecognised sylvatic foci of $T$. infestans have not been detected to date in Pampa del Indio (Alvarado-Otegui et al. 2012, YM Provecho et al., unpublished observations) and remain a less likely additional source. In the present study, active community-based surveillance played a key role in revealing the occurrence of additional foci of $T$. infestans and the ongoing invasion process. This work may be considered as a case study of a more generalised phenomenon occurring in endemic areas with persistent infestation problems in the Gran Chaco. The spatial analysis was also helpful for revealing the spatial relationships between the detected foci and also suggested putative sources.

The findings regarding $\mathrm{TcV}$-infected T. infestans and TcI-infected $T$. sordida in this study are consistent with previous observations in rural communities in the Argentine Chaco. The frequency of TcV-infected domestic T. infestans has been reported to be $16 \%$ in neighbouring rural communities (Maffey et al. 2012) and TcV has frequently been identified in humans (Diosque et al. 2003). TcI has been frequently identified in (peri)domestic $T$. sordida (Maffey et al. 2012) and has rarely been found in dogs and cats in Pampa del Indio (Enriquez et al. 2014).

The baseline, full-coverage assessment of house infestation with timed manual searches corroborated the occurrence of $T$. infestans in the peri-urban area, albeit at 10 -fold lower frequencies than those reported by

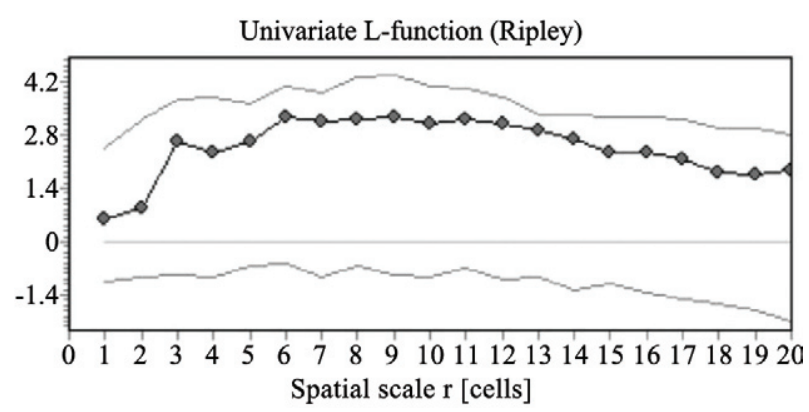

Fig. 5: spatial analysis of householders' reports of triatomine presence in the rapid survey conducted in May 2011, with L-Ripley function and K-function statistic.

householders on two successive occasions. This discrepancy is unlikely to be explained by householders mistaking other insects for triatomines because dry specimens were shown to them to facilitate more accurate identification. More likely explanations are related to recurrent house invasion by flying triatomines (especially $T$. sordida) that failed to establish viable bug colonies in the domiciles and the recollection of past infestations recorded in 2006. A third explanation of the discrepancy might be related to householders' expectation of having their premises sprayed with insecticide if they reported an infestation. The apparently low infestation prevalence recorded at baseline was further corroborated by the follow-up survey and by the occasional discovery of bugs by householders within the framework of the potentially more sensitive community-based surveillance (Abad-Franch et al. 2011). Taken together, the evidence justified selective house sprayings (which apparently suppressed infestations) and not a blanket insecticide spraying of the peri-urban area, which would have required considerable expense and labour.

Although most house infestations were detected in sleeping quarters, high-density bug colonies largely occurred in chicken coops and only in one domicile. The distances between these putative sources and all positive houses with only one-three adult bugs collected were well within the estimated upper limit of the flight range of T. infestans (Schofield et al. 1992). These recent house invasions may also have originated via walking dispersal (Levy et al. 2006, Vázquez-Prokopec et al. 2006, Abrahan et al. 2008) facilitated by the short distance between the houses in the settlement (Fig. 2B). The majority of infested houses occurred in the squatter settlement, where housing quality was precarious (i.e., more vulnerable to bug invasion and colonisation) and the time of residence was less than two years (i.e., bug propagation was in its initial phase).

Peri-urban infestations with $T$. infestans were most frequent in recently built mud-and-grass houses, with more bug refuges, large rural immigrant households, more crowding and more dogs and cats (i.e., the rural poor in search of subsistence). All of these factors related to housing quality and host numbers are positively associated with house infestation with triatomine bugs elsewhere (Cecere et al. 2002, Ramsey et al. 2005, Levy et 
al. 2006, Campbell-Lendrum et al. 2007, Gurevitz et al. 2011). The local residents frequently reported that the increasing rural-to-urban migration during the preceding years was related to the quest for greater access to healthcare services (only provided by the local hospital), electricity, potable water and education. This immigration was balanced between ethnic groups. Taken together, the observed associations suggest that newly arriving immigrants may have transported the bugs from elsewhere, depending on their village of origin and house infestation status at the time of displacement. Immigrant households that originated from rural areas within the municipality of Pampa del Indio (under sustained vector surveillance) were unlikely to transport bugs, whereas the small fraction of immigrants from other rural areas under no vector control showed increased peri-urban house infestation.

Ethnic background was not associated with house infestation, contrasting with a nearby rural section (Gurevitz et al. 2011). However, Qom households mainly used mud or mud-based mortar (allowing faster, less expensive construction) and were of inferior quality, whereas Creole houses mainly had walls made of cement-mortared brick, which is less prone to cracking. The use of mud as a construction material typically creates favourable refuges for domestic triatomine bugs when it cracks and is not appropriately maintained (Mott et al. 1978, Cecere et al. 2002, Levy et al. 2006).

Both the vector surveys and community-based surveillance revealed peridomestic foci of $T$. sordida in chicken coops and its frequent invasion of domestic premises, including frequent contact with humans, as reported by householders. However, the finding of $T$. cruzi-infected $T$. sordida in a peri-urban area was unexpected, although this species was marginally infected in rural areas of Pampa del Indio (Maffey et al. 2012) and elsewhere (Noireau et al. 1997, Diotaiuti et al. 1998).

Our study has certain limitations. Although Firth penalised logistic regression was used for odds ratio estimations in univariate and multivariate analyses, large confidence intervals were nonetheless obtained due to the very low number of event outcomes. Several of the relationships that had prior empirical support showed expressive trends with infestation in the expected direction. The fact that certain evident local clusters of infestation were not statistically significant is in part related to the marginal location of infested houses, at the periphery of the settlement, which reduced the power of global spatial tests. However, a more thorough investigation of the putative sources of peri-urban infestations based on the use of microsatellite genetic markers or geometric morphometry is beyond the scope of our study and would also be limited by the lack of reference samples and the small number of bugs collected.

Our results have implications for vector control. Periurban infestations have been underappreciated and underreported. In Argentina and perhaps in several other countries, Chagas disease vector control programmes usually operate in rural areas, whereas peri-urban or urban areas fall within the rule and responsibilities of local municipalities, which historically have been reluctant to address the problem of house infestation and control of triatomine bugs in urbanised areas. Furthermore, municipalities do not report house infestation or vector control actions to the Ministry of Health and vector control programmes usually report aggregate figures at larger geographic scales. The few published reports of peri-urban house infestation with the major vectors of $T$. cruzi most likely are the tip of the iceberg of a hidden process with political implications. Peri-urban infestations are expected to increase along with persistent rural-to-urban migratory flows and unplanned urbanisation in traditionally endemic regions such as the Gran Chaco. Therefore, if all rural villages in the municipality of Pampa del Indio had not been sprayed with insecticides in 2007-2008 and subsequently subjected to sustained vector surveillance and selective control actions, the passive carriage of $T$. infestans bugs to the emerging peri-urban settlements would have been sizable. There is a large human reservoir of $T$. cruzi present and cats and dogs may also play a role as domestic reservoir hosts (Gürtler et al. 2007). Because of the convergence of several risk factors, households in the squatter settlement were at a greater risk of bug invasion and colonisation. The recurrent occurrence of domestic infestations (including T. cruzi-infected bugs) indicates active parasite transmission, human exposure and the need for active vector surveillance and control at the peri-urban interface with rural areas. Increased awareness combined with concerted, focused actions by local healthcare services, vector control programmes and the affected communities are needed for sustainable vector and disease control.

\section{ACKNOWLEDGEMENTS}

To Jorge Nasir and the Chagas Control Program of Chaco (Esteban Ramírez, Claudio Baudín, Nicasio Vargas and Remigio Vargas), for support in field operations, and to Paula Sartor, Cynthia Delgado and Fundación Mundo Sano.

\section{REFERENCES}

Abad-Franch F, Vega MC, Rolón MS, Santos WS, Rojas de Arias A 2011. Community participation in Chagas disease vector surveillance: systematic review. PLoS Negl Trop Dis 5: e1207.

Abrahan LB, Hernández ML, Gorla DE, Catalá SS 2008. Phenotypic diversity of Triatoma infestans at the microgeographic level in the Gran Chaco of Argentina and the Andean valleys of Bolivia. J Med Entomol 45: 660-666.

Albarracín-Veizaga H, de Carvalho ME, Nascimento EM, Rodrigues VL, Casanova C, Barata JM 1999. Chagas disease in an area of recent occupation in Cochabamba, Bolivia. Rev Saude Publica 33: $230-236$.

Alvarado-Otegui JA, Ceballos LA, Orozco MM, Enriquez GF, Cardinal MV, Cura C, Schijman AG, Kitron U, Gürtler RE 2012. The sylvatic transmission cycle of Trypanosoma cruzi in a rural area in the humid Chaco of Argentina. Acta Trop 124: 79-86.

Bayer AM, Hunter GC, Gilman RH, Cornejo del Carpio JG, Naquira C, Bern C, Levy MZ 2009. Chagas disease, migration and community settlement patterns in Arequipa, Peru. PLoS Negl Trop Dis 3: e567.

Bazzani R, Wiese M 2012. Poverty, ecosystems and vector-borne diseases: introduction. In DF Charron, Ecohealth research in practice: innovative applications of an ecosystem approach to health, insight and innovation in international development, Springer, Canada, p. 133-136. 
Campbell-Lendrum DH, Angulo VM, Esteban L, Tarazona Z, Parra GJ, Restrepo M, Restrepo BN, Guhl F, Pinto N, Aguilera G, Wilkinson P, Davies CR 2007. House-level risk factors for triatomine infestation in Colombia. Int J Epidemiol 36: 866-872.

Carrizo Páez R, Pickenhayn J, Carrizo Páez M 2008. Urban Chagas disease in San Juan. Diagnosis, review and proposal for an integrated attack system. Rev Argent Cardiol 76: 480-487.

Cattan PE, Pinochet A, Botto-Mahan C, Acuña MI, Canals M 2002. Abundance of Mepraia spinolai in a periurban zone of Chile. Mem Inst Oswaldo Cruz 97: 285-287.

Cecere MC, Gürtler RE, Canale DM, Chuit R, Cohen JE 2002. Effects of partial housing improvement and insecticide spraying on the reinfestation dynamics of Triatoma infestans in rural northwestern Argentina. Acta Trop 84: 101-116.

Cecere MC, Vázquez-Prokopec GM, Ceballos LA, Boragno S, Zárate JE, Kitron U, Gürtler RE 2013. Improved chemical control of Chagas disease vectors in the dry Chaco region. J Med Entomol 50: 394-403.

Cecere MC, Vázquez-Prokopec GM, Gürtler RE, Kitron U 2006. Reinfestation sources for Chagas disease vector, Triatoma infestans, Argentina. Emerg Infect Dis 12: 1096-1102.

Charron DF 2012. Ecosystem approaches to health for a global sustainability agenda. EcoHealth 9: 256-266.

Chen D, Getis A 1998. Point pattern analysis (PPA). San Diego, USA: Department of Geography, San DiegoState University.

Coura JR, Dias JCP 2009. Epidemiology, control and surveillance of Chagas disease: 100 years after its discovery. Mem Inst Oswaldo Cruz 104 (Suppl. I): 31-40.

Delgado S, Ernst KC, Pumahuanca MLH, Yool SR, Comrie AC, Sterling CR, Gilman RH, Náquira C, Levy MZ, the Chagas Disease Working Group in Arequipa, Peru 2013. A country bug in the city: urban infestation by the Chagas disease vector Triatoma infestans in Arequipa, Peru. Int J Health Geogr 12: 48.

Dias JCP, Silveira AC, Schofield CJ 2002. The impact of Chagas disease control in Latin America - A Review. Mem Inst Oswaldo Cruz 97: 603-612.

Diosque P, Barnabé C, Padilla A, Marco J, Cardozo R, Cimino R, Nasserd J, Tibayrenc M, Basombrío M 2003. Multilocus enzyme electrophoresis analysis of Trypanosoma cruzi isolates from a geographically restricted endemic area for Chagas' disease in Argentina. Int J Parasitol 33: 997-1003.

Diotaiuti L, Azeredo BV, Busek SC, Fernandez AJ 1998. Control of Triatoma sordida in rural peri-domestic environment of the Porteirinha municipality, Minas Gerais, Brazil. Rev Panam Salud Publica 3: 21-25.

Enriquez, GF, Bua J, Orozco MM, Wirth S, Schijman AG, Gürtler RE, Cardinal MV 2014. High levels of Trypanosoma cruzi DNA determined by qPCR and infectiousness to Triatoma infestans support dogs and cats are major sources of parasites for domestic transmission. Infect Genet Evol 25: 36-43.

Gorla DE, Porcasi X, Hrellac H, Catalá SS 2009. Spatial stratification of house infestation by Triatoma infestans in La Rioja, Argentina. Am J Trop Med Hyg 80: 405-409.

Gurevitz JM, Ceballos LA, Gaspe MS, Alvarado-Otegui JA, Enriquez GF, Kitron U, Gürtler RE 2011. Factors affecting infestation by Triatoma infestans in a rural area of the humid Chaco in Argentina: a multimodel inference approach. PLoS Negl Trop Dis 5: e1365.

Gurevitz JM, Gaspe MS, Enriquez GF, Provecho YM, Kitron U, Gürtler RE 2013. Intensified surveillance and insecticide-based control of the Chagas disease vector Triatoma infestans in the Argentinean Chaco. PLoS Negl Trop Dis 7: e2158.
Gurevitz JM, Gaspe MS, Enriquez GF, Vassena CV, Alvarado-Otegui JA, Provecho YM, Mougabure Cueto GA, Picollo MI, Kitron U, Gürtler RE 2012. Unsuspected pyrethroid resistance and control failures of Chagas disease vector in Argentina. $J$ Med Entomol 49: 1379-1386.

Gürtler RE 2009. Sustainability of vector control strategies in the Gran Chaco region: current challenges and possible approaches. Mem Inst Oswaldo Cruz 104 (Suppl. I): 52-59.

Gürtler RE, Ceballos LA, Ordóñez-Krasnowski P, Lanati LA, Stariolo R, Kitron U 2009. Strong host-feeding preferences of the vector Triatoma infestans modified by vector density: implications for the epidemiology of Chagas disease. PLoS Negl Trop Dis 3: e447.

Gürtler RE, Cecere MC, Vázquez-Prokopec GM, Ceballos LA, Gurevitz JM, Fernández MP, Cohen JE 2014. Domestic animal hosts strongly influence human-feeding rates of the Chagas disease vector Triatoma infestans in Argentina. PLoS Negl Trop Dis 8: e2894.

Gürtler RE, Kitron U, Cecere MC, Segura EL, Cohen JE 2007. Sustainable vector control and management of Chagas disease in the Gran Chaco, Argentina. Proc Natl Acad Sci USA 104: 16194-16199.

Guzman-Tapia Y, Ramírez-Sierra MJ, Dumonteil E 2007. Urban infestation by Triatoma dimidiata in the city of Mérida, Yucatán, Mexico. Vector Borne Zoonotic Dis 7: 597-606.

Heize G, Schemper M 2002. A solution to the problem of separation in logistic regression. Stat Med 21: 2409-2419.

Hotez PJ, Botazzi ME, Franco-Paredes C, Ault SK, Periago MR 2008. The neglected tropical diseases of Latin America and the Caribbean: a review of disease burden and distribution and a roadmap for control and elimination. PLoS Negl Trop Dis 2: e300.

Kitron U, Clennon JA, Cecere MC, Gürtler RE, King CH, VazquezProkopeck GM 2006. Upscale or downscale: applications of fine scale remotely sensed data to Chagas disease in Argentina and schistosomiasis in Kenya. Geospat Health 1: 49-58.

Levy MZ, Barbu CM, Castillo-Neyra R, Quispe-Machaca VR, Ancca-Juarez J, Escalante-Mejia P, Borrini-Mayori K, Niemierko M, Mabud TS, Behrman JR, Naquira-Velarde C, the Chagas Disease Working Group in Arequipa, Peru 2014. Urbanization, land tenure security and vector-borne Chagas disease. Proc R Soc Biol Sci 281: 20141003.

Levy MZ, Bowman NM, Kawai V, Waller LA, Cornejo del Carpio JG, Cordova Benzaquen E, Gilman RH, Bern C 2006. Periurban Trypanosoma cruzi-infected Triatoma infestans, Arequipa, Peru. Emerg Infect Dis 12: 1345-1352.

Lima MM, Sarquis O, de Oliveira TG, Gomes TF, Coutinho C, Daflon-Teixeira NF, Toma HK, Britto C, Teixeira BR, D’Andrea PS, Jansen AM, Bóia MN, Carvalho-Costa FA 2012. Investigation of Chagas disease in four periurban areas in northeastern Brazil: epidemiologic survey in man, vectors, non-human hosts and reservoirs. Trans R Soc Trop Med Hyg 106: 143-149.

Maffey L, Cardinal MV, Ordóñez-Krasnowski PC, Lanati LA, Lauricella MA, Schijman AG, Gürtler RE 2012. Direct molecular identification of Trypanosoma cruzi. Discrete typing units in domestic and peridomestic Triatoma infestans and Triatoma sordida from the Argentine Chaco. Parasitology 139: 1570-1579.

Marcet PL, Duffy T, Cardinal MV, Burgos JM, Lauricella MA, Levin MJ, Schijman AG 2006. PCR based screening and lineage identification of Trypanosoma cruzi directly from faecal samples of triatomine bugs from northwestern Argentina. Parasitology 132: 57-65.

Medrano-Mercado N, Ugarte-Fernandez R, Butrón V, Uber-Busek S, Guerra HL, Araújo-Jorge TC, Correa-Oliveira R 2008. Urban transmission of Chagas disease in Cochabamba, Bolivia. Mem Inst Oswaldo Cruz 103: 423-430. 
Mott KE, Muniz TM, Lehman JSJ, Hoff R, Morrow RHJ, Silva de Oliveira T, Sherlock I, Draper CC 1978. House construction, triatomine distribution and household distribution of seroreactivity to Trypanosoma cruzi in a rural community in Northeast Brazil. Am J Trop Med Hyg 27: 1116-1122.

Noireau F, Brenière F, Ordoñez J, Cardozo L, Morochi W, Gutierrez T, Bosseno MF, Garcia S, Vargas F, Yaksic N, Dujardin JP, Peredo C, Wisnivesky-Colli C 1997. Low probability of transmission of Trypanosoma cruzi to humans by domiciliary Triatoma sordida in Bolivia. Trans R Soc Trop Med Hyg 91: 653-656.

Piccinali RV, Canale DM, Sandoval AE, Cardinal MV, Jensen O, Kitron U, Gürtler RE 2010. Triatoma infestans bugs in southern Patagonia, Argentina. Emerg Infec Dis 16: 887-889.

Ramsey JM, Alvear AL, Ordonez R, Muñoz G, Garcia A, Lopez R, Leyva R 2005. Risk factors associated with house infestation by the Chagas disease vector Triatoma pallidipennis in Cuernavaca metropolitan area, Mexico. Med Vet Entomol 19: 219-228.
Schofield CJ, Lehane MJ, McEwen P, Catalá SS, Gorla DE 1992. Dispersive flight by Triatoma infestans under natural climatic conditions in Argentina. Med Vet Entomol 6: 51-56.

Vallvé SL, Rojo H, Wisnivesky-Colli C 1996. Urban ecology of Triatoma infestans in San Juan, Argentina. Mem Inst Oswaldo Cruz 91: 405-408.

Vázquez-Prokopec GM, Ceballos LA, Marcet PL, Cecere MC, Cardinal MV, Kitron U, Gürtler RE 2006. Seasonal variations in active dispersal of natural populations of Triatoma infestans in rural north-western Argentina. Med Vet Entomol 20: 273-279.

WHO - World Health Organization 2007. Reporte sobre la enfermedad de Chagas. TDR/SWG/09. Available from: whqlibdoc.who. int/hq/2007/TDR_SWG_09_spa.pdf.

Wiegand T, Moloney KA 2004. Rings, circles and null-models for point pattern analysis in ecology. Oikos 104: 209-229. 